\title{
Calcium and Magnesium Levels Are down Regulated in Nigerian Children with Autism Spectrum Disorder and Cerebral Palsy
}

\author{
Ishiaq Olayinka Omotosho ${ }^{{ }^{*}}$, Adekunbi Olufunke Akinade ${ }^{1}$, Ikeoluwa Abiola Lagunju² \\ ${ }^{1}$ Department of Chemical Pathology, College of Medicine, University of Ibadan, Ibadan, Nigeria \\ ${ }^{2}$ Department of Paediatrics, College of Medicine, University of Ibadan, Ibadan, Nigeria \\ Email: *iomotosho2014@gmail.com
}

How to cite this paper: Omotosho, I.O., Akinade, A.O. and Lagunju, I.A. (2018) Calcium and Magnesium Levels Are down Regulated in Nigerian Children with Autism Spectrum Disorder and Cerebral Palsy. Neuroscience \& Medicine, 9, 159-170. https://doi.org/10.4236/nm.2018.93016

Received: August 24, 2017

Accepted: September 1, 2017

Published: September 19, 2018

Copyright $\odot 2018$ by authors and Scientific Research Publishing Inc. This work is licensed under the Creative Commons Attribution International License (CC BY 4.0). http://creativecommons.org/licenses/by/4.0/

\section{Open Access}

\begin{abstract}
Autism Spectrum Disorders (ASDs) and Cerebral Palsy (CP) are amongst the leading neurodevelopmental disorders in children worldwide causing diminished quality of life. Unlike CP caused by brain damage affecting muscle tone, movement and motor skills, equivocal report of different genes with varying loci as genetic malformation and genetic modulation by environmental factors have been the focus of attention in the aetiology of ASD. This study investigated levels of toxic metal $(\mathrm{Pb})$ and macro elements ( $\mathrm{Ca}$ and $\mathrm{Mg}$ ) in blood of children with ASD and CP in Nigeria. 8 and 18 Children (aged 2 - 12 years) clinically screened for features of ASD and CP respectively by pediatric neurologist using DMS-IV classification along with 15 age-matched neurologically healthy ones as controls were recruited. Plasma levels of $\mathrm{Ca}$, $\mathrm{Mg}$ and $\mathrm{Pb}$ were determined in the children using Induction Coupled Plasma Mass Spectroscopy (ICP-MS). Results were analyzed using students t-test. The gender difference was not significant in the children $(P=0.216)$ while developmental milestones' abnormalities (stable neck, sitting, crawling and walking) was significantly prevalent among $\mathrm{CP}$ children relative to ASD and normal children $(\mathrm{P}=0.003,0.003,0.003$ and 0.000 respectively); however, abnormality in talking was common in ASD and CP relative to normal children $(P=0.000)$. There was significant difference in educational background of ASD and CP parents relative to those of normal children $(\mathrm{P}=0.025)$. Mean plasma calcium and magnesium levels was significantly reduced in children with ASD $(7.90 \pm 0.17 \mathrm{mg} / \mathrm{dl}, 2.44 \pm 0.07 \mathrm{mg} / \mathrm{dl})$ and CP $(7.26 \pm$ $0.31 \mathrm{mg} / \mathrm{dl}, 2.42 \pm 0.08 \mathrm{mg} / \mathrm{dl})$ in comparison to the controls $(8.97 \pm 0.20 \mathrm{mg} / \mathrm{dl}$ and $3.26 \pm 0.16 \mathrm{mg} / \mathrm{dl}) ;(\mathrm{P}<0.001 ; \mathrm{P}<0.000$ and $\mathrm{P}<0.002 ; \mathrm{P}<0.000)$ respectively. However, mean lead levels in children with CP $(10.38 \pm 1.45 \mu \mathrm{g} / \mathrm{dl})$ were significantly greater than in ASD $(7.92 \pm 1.30 \mu \mathrm{g} / \mathrm{dl})$ and normal children
\end{abstract}


$(6.83 \pm 0.72 \mu \mathrm{g} / \mathrm{dl})(\mathrm{P}<0.433 ; \mathrm{P}<0.047)$. Hypocalcaemia and hypomagnesaemia with concurrent plumbism (more pronounced in CP) was observed in children with ASD and CP in this study).

\section{Keywords}

ASD, CP, Calcium, Magnesium, Lead, Neurodevelopmental Disorders

\section{Introduction}

Autism Spectrum Disorders (ASD) describes a range of conditions classified as neurodevelopmental disorders in the fifth revision of the American Psychiatric Association [1]. It is a disorder characterized by social deficits and communication difficulties, stereotyped or repetitive behaviors and interests, sensory issues, and in some cases cognitive delays that manifest in early childhood [2]. The incidence of autism in the 90's was estimated at 1 in every 110 children [3]; however, recent studies have shown that the incidence is increasing globally with prevalence rates of $1.13 \%$ ( 1 in 88 ) in 2012 to $1.47 \%$ ( 1 of 68) in 2014 in Americans [4] [5] and $0.8 \%$ in 2011 to $2.3 \%$ in 2014 in Nigerians [6] [7] with a preponderance ratio of four males to a female. This global increase of ASDs prevalence cannot be fully explained in spite of advances in diagnostics because of sudden genetic shifts. There is therefore a growing consensus among scientists and clinicians that ASDs is probably caused from an interaction among genes, environment and the brain [8]. Several studies on environmental factors including those on identical twins have implicated either the exposure to toxins or lack of essential trace elements as important contributors in the pathophysiology of ASD [8]. Also, the plausibility of this has been corroborated by identifying roles of these elements and by the equivocal results of various genetic typing in children with ASD [9].

Cerebral palsy is a common developmental disability characterized by motor impairment and can present with general physical and mental dysfunction with worldwide incidence of 2 to 2.5 per 1000 live births [9]. It is a static neurologic condition resulting from brain injury that occurs before cerebral development is complete. Because brain development continues during the first two years of life, cerebral palsy can result from brain injury occurring during the prenatal, perinatal, or postnatal periods. The etiology of CP is therefore very diverse and multifactorial. The causes are diverse; they include congenital, genetic, inflammatory, infectious, anoxic, traumatic and metabolic. The injury to the developing brain may be prenatal, natal or postnatal. As much as $75 \%-80 \%$ of the cases are due to prenatal injury with less than $10 \%$ being due to significant birth trauma or asphyxia [10].

Trace elements are the building blocks of our bodies which consist of macro elements that are required in milligram quantities and the micro elements that 
are needed in micro and possibly nano quantities. They are required especially as coenzymes in many metabolic processes and also as building blocks for body and protein structure, fluid balance and many other processes in the body. They are keys for the health of every body system and functions [11]. Most of the essential trace elements are derived from diet; however, a good number are environmental contaminants/toxicants which inevitably find their way into the human system. Genetically, children with autism may be less able to detoxify toxic environmental agents, and this inability may predispose them to suffer neural damage consistent with autistic behavioral traits [12]. There have been suggestions that lack of essential minerals may cause many health problems, and a lack of them (or in some cases, an excess of them) could contribute to the etiology of ASD. This study was therefore designed to investigate the possible presence and role of abnormal levels of toxic $(\mathrm{Pb})$ and macro elements $(\mathrm{Mg}$ and $\mathrm{Ca})$ in the blood of children with ASD and those with CP.

\section{Subjects and Methods}

Recruitment: A total number of 41 participants were recruited for this pilot study. This comprised of eight (8) and eighteen (18) clinically diagnosed ASD and CP participants with mean age $5.25 \pm 0.37$ and $5.47 \pm 0.81$ respectively and fifteen (15) neurological healthy children with mean age $7.87 \pm 0.89$ as controls. Children with CP were included in this study to serve as positive control because $\mathrm{CP}$ is more prevalent and have also been well investigated. Distinguishing features of children with $\mathrm{CP}$ in respect of developmental milestones make the diagnosis clearer than ASD thus using $\mathrm{CP}$ as eliminating criterion while investigating neurodevelopmental disorders identification and hence recognition of ASD.

Selection: Selection of subjects was done by the Paediatric Neurologist based on above criteria and all autistic children were subjected to a full clinical child psychiatric evaluation for diagnosis of autistic spectrum disorder and exclusion of other psychiatric disorders according to Diagnostic and Statistical Manual of Mental Disorders based on DSM-IV-TR; DSM-5 classification. All the children recruited for the study received routine childhood vaccinations.

History of all children in the study was taken covering: parent socio-economic status, pregnancy history, attainment of developmental milestones, dietary history, and environmental exposure details. Past history of major childhood illnesses and immunizations were taken and clinical examination of all body systems with special emphasis on neurological examination was performed.

Ethical approval was obtained from the University of Ibadan/University College Hospital joint Ethical Committee.

Informed consent was obtained from each subject through their parents.

Inclusion criteria: Children clinically diagnosed as ASD and those as CP whose parents gave informed consent were recruited for the study.

Exclusion criteria: Children having liver or kidney disease, anemia, kwashi- 
orkor or current treatment for iron deficiency, progressive neurological disorders, or epilepsy were excluded from the study.

\section{Method}

Blood collection: About $2 \mathrm{mls}$ of venous blood sample was collected from each participant from the ante-cubital vein. Blood was carefully dispensed into lithium heparin bottles to avoid haemolysis. Blood samples were centrifuged at 2000r.p.m. for 10 minutes using Centaur 2-centrifuge (Fiston centrifuge, manufactured in England) to obtain plasma which was promptly separated into another clean plane bottle. All samples were kept frozen at $-20^{\circ} \mathrm{C}$ until they were ready for analysis.

$\mathrm{Ca}, \mathrm{Mg}$ and $\mathrm{Pb}$ were determined using ICP-MS.

\section{Results}

Instrument software was used on the machine to calculate the results with the inclusion of appropriate standard and controls. The result was in part per billion (ppb); concentrations in ppb were converted to other units using appropriate conversion factor. Details of the results are in Tables 1-6.

Statistical analysis: Data obtained were revised, coded, tabulated, and analyzed using Statistical Package for Social Science (SPSS 20.0.1 for windows; SPSS Inc., Chicago, IL, 2016) according to the type of data obtained for each parameter.

Descriptive statistics: Mean standard error $( \pm \mathrm{SE})$ was used for parametric numerical data, frequency and percentage for non-numerical data.

Analytical statistics: Student's t-test was used to assess the statistical significance of the difference between two study group means. ANOVA was used to assess the statistical significance of the difference between more than two study group means, chi-square test was used to examine the relationship between two qualitative variables, and fisher's exact test was used to examine the relationship between two qualitative variables when the expected count was less than 5 in more than $20 \%$ of cells. P value of 0.05 was considered significant.

Table 1 shows ASD group consisted of 6 boys (75\%) and 2 girls (25\%); CP consisted of 15 boys (83.3\%) and 3 girls (16.7\%) and the control group consisted of 8 boys (53.3\%) and 7 girls (46.7\%). Analysis of the questionnaires showed that $75.0 \%$ of ASD and $66.7 \%$ of CP were 1st child among siblings. Deductions from the result showed that parents of the children in the 3 groups belong to similar socio-economic class however fathers of $\mathrm{CP}$ children were least educated.

Table 2 shows profile of developmental milestones in the participants. $62.5 \%$ of ASD and $77.8 \%$ of children with CP were not talking; this value is significant when compared within the groups $(\mathrm{P}<0.000) .38 .9 \%$ of children with $\mathrm{CP}$ had unstable neck with delayed sitting and crawling $(\mathrm{P}<0.003)$ while $55.6 \%$ were not walking. The other developmental milestones indicators showed that children with CP were significantly affected compared to children with ASD and none in 
Table 1. Comparison of frequency distribution of socio-economic status within the group using chi-square.

\begin{tabular}{ccccccc}
\hline VARIABLES & RESPONSE & $\begin{array}{c}\text { ASD } \\
(\mathrm{N}=8)\end{array}$ & $\begin{array}{c}\mathrm{CP} \\
(\mathrm{N}=18)\end{array}$ & $\begin{array}{c}\mathrm{NC} \\
(\mathrm{N}=15)\end{array}$ & $X^{2}$ & P-value \\
\hline \multirow{2}{*}{ SEX } & MALE & $6(75 \%)$ & $15(83.3 \%)$ & $8(53.3 \%)$ & 3.644 & 0.216 \\
& FEMALE & $2(25 \%)$ & $3(16.7 \%)$ & $7(46.7 \%)$ & & \\
& 1ST & $6(75.0 \%)$ & $12(66.7 \%)$ & $8(53.3 \%)$ & & \\
CHILD & 2ND & $2(25.0 \%)$ & $2(11.1 \%)$ & $2(13.3 \%)$ & & \multirow{2}{*}{0.686} \\
BIRTH & 2ND & $0(0.0 \%)$ & $0(0.0 \%)$ & $2(13.2 \%)$ & \multirow{2}{*}{8.141} & \\
ORDER & 3RD & $0(0.0 \%)$ & $2(11.1 \%)$ & $3(20.0 \%)$ & & \\
& 4TH & $0(0.0 \%)$ & $1(5.6 \%)$ & $0(0.0 \%)$ & & \\
& STH & $0(0.0 \%)$ & $1(5.6 \%)$ & $0(0.0 \%)$ & & \\
MOTHER'S & PE & $0(0.0 \%)$ & $2(11.1 \%)$ & $0(0.0 \%)$ & & \\
LEVEL OF & PPE & $1(12.5 \%)$ & $6(33.3 \%)$ & $4(26.7 \%)$ & \multirow{2}{*}{8.118} & \\
EDUCATION & PSE & $5(62.5 \%)$ & $9(50.0 \%)$ & $5(33.3 \%)$ & & \\
& PGE & $2(25.0 \%)$ & $1(5.6 \%)$ & $6(40.0 \%)$ & & \\
FATHER'S & PE & $0(0.0 \%)$ & $1(5.6 \%)$ & $0(0.0 \%)$ & & \\
LEVEL OF & PPE & $1(12.5 \%)$ & $5(27.8 \%)$ & $3(20.0 \%)$ & \multirow{2}{*}{$14.395^{\#}$} & $0.025^{\star}$ \\
EDUCATION & PSE & $5(62.5 \%)$ & $11(61.1 \%)$ & $3(20.0 \%)$ & & \\
& PGE & $2(25.0 \%)$ & $1(5.6 \%)$ & $9(60.0 \%)$ & & \\
\hline
\end{tabular}

"Fisher's Exact Test, * ${ }^{*}$ significant at $\mathrm{P}<0.05$ (PE-Primary Education; PPE-Post Primary Education; PSE-Post Secondary Education; PGE-Post Graduate).

Table 2. Comparison of frequency distribution of developmental milestones within the group using chi-square.

\begin{tabular}{ccccccc}
\hline VARIABLES & RESPONSE & $\begin{array}{c}\text { ASD } \\
(\mathrm{N}=8)\end{array}$ & $\begin{array}{c}\mathrm{CP} \\
(\mathrm{N}=18)\end{array}$ & $\begin{array}{c}\mathrm{NC} \\
(\mathrm{N}=15)\end{array}$ & $X^{2}$ & P-value \\
\hline STABLE & YES & $8(100 \%)$ & $11(61.1 \%)$ & $15(100 \%)$ & $9.390^{*}$ & $0.003^{*}$ \\
NECK & NO & $0(0.0 \%)$ & $7(38.9 \%)$ & $0(0.0 \%)$ & & \\
& YES & $8(100 \%)$ & $11(61.1 \%)$ & $15(100 \%)$ & $9.390^{*}$ & $0.003^{*}$ \\
SITTING & NO & $0(0.0 \%)$ & $7(38.9 \%)$ & $0(0.0 \%)$ & & \\
& YES & $8(100 \%)$ & $11(61.1 \%)$ & $15(100 \%)$ & $9.390^{*}$ & $0.003^{*}$ \\
WAWLING & NO & $0(0.0 \%)$ & $7(38.9 \%)$ & $0(0.0 \%)$ & & \\
& YES & $8(100 \%)$ & $8(44.4 \%)$ & $15(100 \%)$ & $17.348^{*}$ & $0.000^{*}$ \\
\multirow{2}{*}{ TALKING } & NO & $0(0.0 \%)$ & $10(55.6 \%)$ & $0(0.0 \%)$ & & \\
& YES & $3(37.5 \%)$ & $4(22.2 \%)$ & $15(100 \%)$ & $23.487^{*}$ & $0.000^{*}$ \\
\hline
\end{tabular}

${ }^{*}$ Fisher's Exact Test, ${ }^{*}$ significant at $\mathrm{P}<0.05$.

controls. Deduction from these data showed that developmental milestones were either delayed or impaired in children with ASD and CP compared to control.

Table 3 shows that there were no significant differences in dietary and nutrition patterns of the three groups except for the nutritional supplement which revealed that $61.1 \%$ of children with $\mathrm{CP}$ were not taking nutritional supplement $(\mathrm{P}<0.001)$. The level of education of parents of the children might have influenced administration of supplements towards enhancing the level of nutritional elements in the children.

Table 4 shows biodata variables among children with ASD, CP and controls. 
Table 3. Comparison of frequency of nutrition/dietary history within the groups using chi-square.

\begin{tabular}{|c|c|c|c|c|c|c|}
\hline VARIABLES & RESPONSE & $\begin{array}{c}\text { ASD } \\
(\mathrm{N}=8)\end{array}$ & $\begin{array}{c}\mathrm{CP} \\
(\mathrm{N}=18)\end{array}$ & $\begin{array}{c}\mathrm{NC} \\
(\mathrm{N}=15)\end{array}$ & $X^{2}$ & $\mathrm{P}$-value \\
\hline \multirow{3}{*}{$\begin{array}{l}\text { FRUITS AND } \\
\text { VEGETABLES }\end{array}$} & DAILY & $4(50.0 \%)$ & $8(44.4 \%)$ & $5(33.3 \%)$ & \multirow{3}{*}{$1.726^{\#}$} & \multirow{3}{*}{0.849} \\
\hline & WEEKLY & $3(37.5 \%)$ & $8(44.4 \%)$ & $9(60.0 \%)$ & & \\
\hline & OCCASIONALLY & $1(12.5 \%)$ & $2(11.1 \%)$ & $1(6.7 \%)$ & & \\
\hline \multirow{4}{*}{$\begin{array}{l}\text { NUTRITIONAL } \\
\text { SUPPLEMENTS }\end{array}$} & DAILY & $3(37.7 \%)$ & $5(27.8 \%)$ & $0(0.0 \%)$ & \multirow{4}{*}{$19.520^{\#}$} & \multirow{4}{*}{$0.001^{\star}$} \\
\hline & WEEKLY & $2(25.0 \%)$ & $0(0.0 \%)$ & $7(46.7 \%)$ & & \\
\hline & OCCASIONALLY & $2(25.0 \%)$ & $2(11.1 \%)$ & $4(26.7 \%)$ & & \\
\hline & NONE USERS & $1(12.5 \%)$ & $11(61.1 \%)$ & $4(26.7 \%)$ & & \\
\hline \multirow{4}{*}{ SEA FOOD } & DAILY & $5(62.5 \%)$ & $11(61.1 \%)$ & $4(26.7 \%)$ & \multirow{4}{*}{$7.829^{\#}$} & \multirow{4}{*}{0.197} \\
\hline & WEEKLY & $090.0 \%)$ & $0(0.0 \%)$ & $2(13.3 \%)$ & & \\
\hline & OCCASIONALLY & $2(25.0 \%)$ & $3(16.7 \%)$ & $7(46.7 \%)$ & & \\
\hline & NONE USERS & $1(12.5 \%)$ & $4(22.2 \%)$ & $2(13.3 \%)$ & & \\
\hline \multirow{3}{*}{$\begin{array}{l}\text { SUUPLEMENT } \\
\text { IN PREGNANCY }\end{array}$} & DAILY & $7(87.5 \%)$ & $18(100 \%)$ & $13(86.7 \%)$ & \multirow{3}{*}{4.233} & \multirow{3}{*}{0.252} \\
\hline & WEEKLY & $1(12.5 \%)$ & $0(0.0 \%)$ & $1(6.7 \%)$ & & \\
\hline & NONE USERS & $0(0.00 \%)$ & $0(0.0 \%)$ & $1(6.7 \%)$ & & \\
\hline
\end{tabular}

"Fisher's Exact Test, ${ }^{*}$ significant at $\mathrm{P}<0.05$.

Table 4. Comparison of biodata variables within the three group using anova (Mean \pm S.E.).

\begin{tabular}{cccccc}
\hline VARIABLES & $\begin{array}{c}\text { ASD } \\
(\mathrm{N}=8)\end{array}$ & $\begin{array}{c}\text { CP } \\
(\mathrm{N}=18)\end{array}$ & $\begin{array}{c}\text { CONTROL } \\
(\mathrm{N}=15)\end{array}$ & F-VALUE & P-VALUE \\
\hline Child's age (yrs) & $5.25 \pm 0.37$ & $5.47 \pm 0.81$ & $7.87 \pm 0.89$ & 2.961 & 0.064 \\
Mother's age at birth (yrs) & $28.63 \pm 1.59$ & $30.50 \pm 1.14$ & $30.24 \pm 1.29$ & 0.575 & 0.567 \\
Father's age at birth (yrs) & $32.88 \pm 1.60$ & $37.22 \pm 1.94$ & $34.40 \pm 1.097$ & 1.089 & 0.347 \\
Child's weight (kg) & $19.31 \pm 0.61$ & $16.38 \pm 1.81$ & $19.67 \pm 2.22$ & 0.937 & 0.401 \\
Child's birth weight (kg) & $3.38 \pm 0.07$ & $2.86 \pm 0.18$ & $2.86 \pm 0.23$ & 1.591 & 0.217 \\
\hline
\end{tabular}

There were no significant differences in children's age, mother's age at birth, father's age at birth, children's birth weight and children's weight between ASD and CP. It may therefore be said that there was no disparity in recorded bio data of the participants which might have influenced the study.

Table 5 shows the comparison of plasma levels of $\mathrm{Mg}, \mathrm{Ca}$ and $\mathrm{Pb}$ in children with ASD and Control.

The mean plasma calcium and magnesium concentration in children with ASD were $7.90 \pm 0.17 \mathrm{mg} / \mathrm{dl}$ and $2.44 \pm 0.07 \mathrm{mg} / \mathrm{dl}$ respectively. These were significantly reduced when compared to $8.97 \pm 0.20$ and $3.26 \pm 0.16 \mathrm{mg} / \mathrm{dl}$ in control ( $\mathrm{P}<0.001 ; \mathrm{P}<0.002$ respectively). Although, the mean plasma lead levels in children with ASD was increased $(7.92 \pm 1.30 \mu \mathrm{g} / \mathrm{dl})$ when compared with control $(6.83 \pm 0.72 \mu \mathrm{g} / \mathrm{dl})$, the difference was not significant $(\mathrm{P}<0.433)$. Hypocalcaemia and hypomagnasaemia maybe implied from this results.

Table 6 shows the comparison of plasma levels of $\mathrm{Mg}$, $\mathrm{Ca}$ and $\mathrm{Pb}$ between children with $\mathrm{CP}$ and Control. The mean plasma calcium and magnesium 
Tables 5. Comparison of biodata variables, trace and toxic metals in asd and control (Mean \pm S.E.).

\begin{tabular}{ccccc}
\hline VARIABLES & $\begin{array}{c}\text { ASD } \\
(\mathrm{N}=8)\end{array}$ & $\begin{array}{c}\text { CONTROL } \\
(\mathrm{N}=15)\end{array}$ & t-value & P-value \\
\hline Magnesium $(\mathrm{mg} / \mathrm{dl})$ & $2.44 \pm 0.07$ & $3.26 \pm 0.16$ & -3.669 & $0.001^{*}$ \\
Calcium $(\mathrm{mg} / \mathrm{dl})$ & $7.90 \pm 0.17$ & $8.97 \pm 0.20$ & -3.616 & $0.002^{*}$ \\
Lead $(\mu \mathrm{g} / \mathrm{dl})$ & $7.92 \pm 1.30$ & $6.83 \pm 0.72$ & 0.799 & 0.433 \\
\hline
\end{tabular}

*Significant at $\mathrm{P}<0.05$.

Table 6. comparison of biodata variables, trace and toxic metals in children with cp and control (Mean \pm S.E.).

\begin{tabular}{ccccc}
\hline VARIABLES & $\begin{array}{c}\mathrm{CP} \\
(\mathrm{N}=18)\end{array}$ & $\begin{array}{c}\text { CONTROL } \\
(\mathrm{N}=15)\end{array}$ & t-value & P-value \\
\hline Magnesium $(\mathrm{mg} / \mathrm{dl})$ & $2.42 \pm 0.08$ & $3.26 \pm 0.16$ & -4.966 & $0.000^{\star}$ \\
Calcium $(\mathrm{mg} / \mathrm{dl})$ & $7.26 \pm 0.31$ & $8.97 \pm 0.20$ & -4.439 & $0.000^{\star}$ \\
Lead $(\mu \mathrm{g} / \mathrm{dl})$ & $10.38 \pm 1.45$ & $6.83 \pm 0.72$ & 2.070 & $0.047^{\star}$ \\
\hline
\end{tabular}

*Significant at $\mathrm{P}<0.05$.

concentration in children with CP were $7.26 \pm 0.31 \mathrm{mg} / \mathrm{dl}$ and $2.42 \pm 0.08 \mathrm{mg} / \mathrm{dl}$ respectively. These were significantly reduced when compared to $8.97 \pm 0.20$ and $3.26 \pm 0.16 \mathrm{mg} / \mathrm{dl}$ in control $(\mathrm{P}<0.000 ; \mathrm{P}<0.000)$. Unlike in children with ASD, the mean plasma lead levels in children with $\mathrm{CP}(10.38 \pm 1.45 \mu \mathrm{g} / \mathrm{dl})$ were significantly increased when compared with the control $(6.83 \pm 0.72 \mu \mathrm{g} / \mathrm{dl})(\mathrm{P}<$ 0.047). Plumbism may be implied in children with $\mathrm{CP}$ with this result.

\section{Discussion}

Neurological disorders constitute a quarter of the top 20 health conditions leading to reported disability in about 1 billion people world-wide [13], ASD and CP are leading amongst these disorders; the prevalence rates is on the increase in developing countries just as in the developed countries. ASD, a known neurodevelopmental disorder, is characterized by dysfunctions in social, communications and repetitive behaviours. Its prevalence is reported to be $1.47 \%$ ( 1 of 68 ) in Americans [5] and 2.3\% in Nigerian children [7]; the upsurge of the disorder in recent time has been of concern due to its undefined pathophysiology. There is therefore a growing interest in understanding the pathophysiology of the implication of environmental pollutants and micronutrients status in the aetiology of ASD. Cerebral palsy is a static neurologic condition resulting from brain injury that occurs before cerebral development is complete. Because brain development continues during the first two years of life, cerebral palsy can result from brain injury occurring during the prenatal, perinatal, or postnatal periods [12]. This study was designed to determine the plasma levels of $\mathrm{Ca}, \mathrm{Mg}$ and $\mathrm{Pb}$ in these neurodevelopmental disorders (ASD and CP) towards assessing their possible contribution in the aetiopathogenesis of these disorders. 
The significantly decreased level of magnesium observed in children with ASD and CP when compared with control in this study may be associated with gross abnormality in axon development and stabilization. Magnesium is an essential mineral that is necessary for the health of every cell in the body, including the proper functioning of brain and muscle cells. It is a macro element associated with axon development and stabilization. Amongst the known functions of axons in neural transmission is impulse carriage which ensures transmission of signals from one neuron to the other [14]. Although calcium is the element that regulates transmission of electrical signals in nerves, it's been reported that magnesium regulates entrance of calcium into the nerve cells [15]. Hence, a reduction in the level of $\mathrm{Mg}$ as observed in this study may be an impediment in the transmission of signals the manifestation of which may be the characteristic repetitive behaviour in children with ASD. Reports have shown that the earliest manifestations of magnesium deficiency are usually neuromuscular and neuropsychiatric disturbances [14]. Previous reports have also shown that magnesium protects cells from toxic metals and oxy-radical damage while assisting in the absorption and metabolism of vitamins $\mathrm{C}$ and $\mathrm{E}$ which are anti-oxidants important in cell protection [16]. Therefore, the consequence of a reduced level of $\mathrm{Mg}$ may include disturbance in the absorption of some of the other essential metals that may be needed for the basic functions of the neuron. Although, there are limited number of works on trace metals levels in neurodevelopmental disorders generally, most work on ASD were on hair and nail. In a similar study by Marlowe et al. (1983) [17], a significantly lower level of magnesium in the hair of autistic children was reported. However, the study by Melendez et al. (2013) [18] that reported a low serum magnesium level in ASD compared to reference value was similar to finding in this study.

On the other hand, the protective effect of $\mathrm{Mg}$ on the preterm neonatal brain particularly against CP may be inferred from studies on tocolysis. Previous studies showed that infants born to mothers given magnesium sulphate to prevent eclamptic seizures or as tocolysis showed a reduction in rates of cerebral palsy [19] [20]. The role of magnesium as a neuroprotective element in the development of CP may therefore be imperative; hence, the markedly reduced $\mathrm{Mg}$ level which was observed in children with CP and ASD may be prognostic of these neurodevelopmental disorders.

Also, the reduced Calcium level found in both children with ASD and CP in comparison to the controls may be as a result of reduced magnesium levels since both metals are known to be mostly interdependent in their activities [15]. Calcium regulation has been known to play a major role in neurodevelopment and synaptic plasticity [21]. It is crucial for the transmission of electrical signal along the nerves hence a reduction in calcium level may precipitate abnormality in signal transmission along the nerves and the developing neurons. The abnormality in the developing neuron will largely manifest as an abnormality in neurite outgrowth, a section of the neuron crucial for neural transmission; this may 
explain the repetitive behavior in children with ASD. The tendency for this development may be due to the function of extracellular calcium-sensing receptor (CASR) present in the brain which is responsive to prevailing levels of extracellular calcium [22]. Thus, chronic or intermittent hypocalcemia in the patients may have a deleterious effect on neurite outgrowth and synaptogenesis, which may predispose these patients to neurodevelopmental alterations that ultimately manifest as neuropsychiatric sequela. Although the mechanism is unknown, previous workers have reported accumulating evidence for a causal role of calcium dysregulation in ASD. Such works clearly implicate calcium dysregulation as one of the most prominent biological factors in neurodevelopmental disorders risk when both genetic and environmental factors are considered [23] [24].

Lead level found in this study was increased in children with neurodevelopmental disorders compared to controls. Sources of exposure of the participants in this study to lead may be dust from the environment; this was amply demonstrated by the analysis of the questionnaire which showed that $37.5 \%$ (ASD) and $77.4 \%$ (CP) of the participants have their house situated on an untarred road. Tong and others (2010) reported that sources of exposure to lead include leaded gasoline, leaded paint, dust and soil contaminated with lead, water carried in lead pipes, industrial emissions or occupational exposures [25]. Lead $\left(\mathrm{Pb}^{2+}\right)$ has been shown to induce cognitive and behavioral deficits in children and adult with elevated levels of exposure resulting in a distinct neurological effects, with different brain targets and modes of action [26] [27]. Children are more vulnerable to air-borne metallic lead than adults since their respiration and metabolic rates are higher than in adults [13] (WHO, 2011), the toxic effect is thus more pronounced in children where it interferes with the normal development of a child's brain and nervous system. Previous studies done on hair reported increased lead levels in ASD compared to controls [9] [12] [27] just as it has been observed in this study that lead levels in ASD was higher than in control. The higher preponderance of $\mathrm{Pb}$ level in children with $\mathrm{CP}$ in comparison to those with ASD may be inferred from the residential locations of the children as deduced from the questionnaire. It could be seen that a greater percentage of children with $\mathrm{CP}$ lived nearer untarred road. Overall, exposure to $\mathrm{Pb}$ observed in this study agreed with other studies [28] [29] [30] [31]. They all reported increased blood lead levels in children with ASD. Secondly, calcium has also been reported to be selectively displaced by lead when the latter is in excess [32]; hence, the increased lead level in this study may be precipitated by the hypocalcaemia earlier observed in children with ASD and CP in this study. Nutritionally, children with ASD displayed lower levels of the essential elements calcium, copper, magnesium and selenium [33]. Since autistic children display poor eating habits; the low tissue levels may be explained by an inadequate nutritional intake.

The pathophysiology of ASD may also be due to increased blood lead level observed in this study which has been implicated in disturbance in the redox ac- 
tivity of the brain. This is because increased blood lead level has been reported to have a variety of effects on synaptic mechanisms and structures resulting in formation of reactive oxygen species, speeding mitochondrial self-destruction through formation of the permeability transition pore, and priming activation of programmed cell death processes [31]. Increased blood level also interferes with neurotransmitter release, disrupting the function of GABAergic, dopaminergic, and cholinergic systems [31]. It has also been suggested that children with ASD show greater concentration of potentially toxic metal $\mathrm{Pb}$ in tissue; this may be the result of a greater ability to accumulate toxins, which in turn leads to an alteration of biochemical processes. It may therefore be inferred that children with neurodevelopmental disorders particularly ASD and CP may have problems with the chemical pathway that allows them to detoxify metals [15].

\section{Conclusion}

Based on the results of the present study it may be concluded that the levels of $\mathrm{Mg}$ and $\mathrm{Ca}$ which are essential macro metals were reduced and toxic metal $(\mathrm{Pb})$ was increased in neurodevelopmental disorders as manifested in children with ASD and CP. Comparatively, there was an inverse relationship between the level of toxic metals and the essential macro elements; the ratio is more severe in $\mathrm{CP}$ than in ASD. The study thus suggests that the toxic effect of lead and reduced levels of the macro elements $\mathrm{Ca}$ and $\mathrm{Mg}$ may be prognostic of these neurodevelopmental disorders.

\section{Conflicts of Interest}

The authors declare no conflicts of interest regarding the publication of this paper.

\section{References}

[1] APA (2013) American Psychiatric Association's Diagnostic and Statistical Manual of Mental Disorders. 5th Edition (DSM-5).

[2] (2013) Autism Spectrum Disorder Fact Sheet, American Psychiatric Publishing, Arlington, VA. http://www.dsm5.org/

[3] Gillberg, C. and Wing, L. (1999) Autism: Not an Extremely Rare Disorder. Acta Psychiatrica Scandinavica, 99, 399-406. https://doi.org/10.1111/j.1600-0447.1999.tb00984.x

[4] CDC (2012) Prevalence of Autism Spectrum Disorders-Autism and Developmental Disabilities Monitoring Network, 14 Sites, United States, 2008. MMWR 2012, 61 (No. SS-3).

[5] CDC (2014) Prevalence of Autism Spectrum Disorder among Children Aged 8 Years-Autism and Developmental Disabilities Monitoring Network, 11 Sites, United States, 2010. Surveillance Summaries, 63, 1-21.

[6] Bakare, M.O. and Munir, K.M (2011) Autism Spectrum Disorders in Africa. In: Mohammadi, M.-R., Ed., A Comprehensive Book on Autism Spectrum Disorders, Chapter 10, In Tech. http://www.intechopen.com/articles/show/title/autism-spectrum-disorders-in-africa 
[7] Lagunju, I.A., Bella-Awusah, T.T. and Omigbodun, O.O. (2014) Autistic Disorder in Nigeria: Profile and Challenges to Management. Epilepsy \& Behavior, 39, 126-129.

[8] Tordjman, S., Somogyi, E., Coulon, N., Kermarrec, S., Cohen, D., Bronsard, G., Bonnot, O., Weismann-Arcache, C., Botbol, M., Lauth, B., Ginchat, V., Roubertoux, P., Barburoth, M., Kovess, V., Geoffray, M.-M. and Xavier, J. (2014) Gene $\times$ Environment Interactions in Autism Spectrum Disorders: Role of Epigenetic Mechanisms. Frontiers in Psychiatry, 5, 53. https://doi.org/10.3389/fpsyt.2014.00053

[9] Adams, J.B., Audhya, T., McDonough-Means, S., Rubin, R.A., Quig, D., Geis, E., et al. (2013) Toxicological Status of Children with Autism vs. Neurotypical Children and the Association with Autism Severity. Biological Trace Element Research, 151, 171-180. https://doi.org/10.1007/s12011-012-9551-1

[10] Arneson, C.L., Durkin, M.S., Benedict, R.E., Kirby, R.S., Yeargin-Allsopp, M., Van Naarden Braun, K. and Doernberg, N.S. (2009) Prevalence of Cerebral Palsy: Autism and Developmental Disabilities Monitoring Network, Three Sites, United States, 2004. Disability and Health Journal, 2, 45-48. https://doi.org/10.1016/j.dhjo.2008.08.001

[11] Krigger, KW. (2006) Cerebral Palsy: An Overview. American Family Physician, 73, 91-100.

[12] Geier, D.A., Kern, J.K., Garver, C.R., et al. (2009) Biomarkers of Environmental Toxicity and Susceptibility in Autism. Journal of the Neurological Sciences, 280, 101-108. https://doi.org/10.1016/j.jns.2008.08.021

[13] World Health Organization (2011) http://www.who.int/disabilities/world_report/2011/en/index.html

[14] Long, S. and MP Romani, A. (2014) Role of Cellular Magnesium in Human Diseases. Austin Journal of Nutrition and Food Sciences, 2, 1051.

[15] Lakshmin Priya, M.D. and Geetha, A. (2011) Levels of Trace Elements (Copper, Zinc, Magnesium and Selenium) and Toxic Elements (Lead and Mercury) in the Hair and Nail of Children with Autism. Biological Trace Element Research, 142, 148-158.

[16] Barbagallo, M., et al. (1999) Effects of Vitamin E and Glutathione on Glucose Metabolism: Role of Magnesium. Hypertension, 34, 1002-1006.

https://doi.org/10.1161/01.HYP.34.4.1002

[17] Marlowe, M., Errera, J. and Jacobs, J. (1983) Increased Lead and Cadmium Burdens among Mentally Retarded Children and Children with Borderline Intelligence. American Journal of Mental Deficiency, 87, 477-483.

[18] Melendez, L., dos Santos, D., Polido, L., Mendes, M.L., Sella, S., et al. (2013) Aluminium and Other Metals May Pose a Risk to Children with Autism Spectrum Disorder: Biochemical and Behavioural Impairments. Clinical and Experimental Pharmacology and Physiology, 3, 120. https://doi.org/10.4172/2161-1459.1000120

[19] Doyle, L.W., Crowther, C.A., Middleton, P., Marret, S. and Rouse, D. (2009) Magnesium Sulphate for Women at Risk of Preterm Birth for Neuroprotection of the Fetus. Cochrane Database of Systematic Reviews, No. 1, CD004661.

[20] D’Souza, R. and Bhide, A. (2011) Magnesium Sulfate and Protecting against Cerebral Palsy?

[21] Lohmann, C. and Bonhoeffer, T. (2008) A Role for Local Calcium Signaling in Rapid Synaptic Partner Selection by Dendritic Filopodia. Neuron, 59, 253-260. https://doi.org/10.1016/j.neuron.2008.05.025 
[22] Liu, X.L., Lu, Y.S., Gao, J.Y., Marshall, C., Xiao, M., Miao, D.S., et al. (2013) Calcium Sensing Receptor Absence Delays Postnatal Brain Development via Direct and Indirect Mechanisms. Molecular Neurobiology, 48, 590-600. https://doi.org/10.1007/s12035-013-8448-0

[23] Napolioni, V., Persico, A.M., Porcelli, V. and Palmieri, L. (2011) The Mitochondrial Aspartate/Glutamate Carrier AGC1 and Calcium Homeostasis: Physiological Links and Abnormalities in Autism. Molecular Neurobiology, 44, 83-92. https://doi.org/10.1007/s12035-011-8192-2

[24] Zeidán-Chuliá, F., Rybarczyk-Filho, J.L., Salmina, A.B., de Oliveira, B.-H.N., Noda, M. and Moreira, J.C.F. (2013) Exploring the Multifactorial Nature of Autism through Computational Systems Biology: Calcium and the Rho GTPase RAC1 under the Spotlight. NeuroMolecular Medicine, 1-20.

https://doi.org/10.1007/s12017-013-8224-3

[25] Tong, S., Anthony, J., McMichael and Baghurst, P.A. (2010) Interactions between Environmental Lead Exposure and Social Demographic Factors on Cognitive Development. Archives of Environmental Health, 55, 330-335.

[26] Lanphear, B.P., Hornung, R., Khoury, J., Yolton, K., Baghurst, P., et al. (2005) Low-Level Environmental Lead Exposure and Children's Intellectual Function: An International Pooled Analysis. Environmental Health Perspectives, 113, 894-899. https://doi.org/10.1289/ehp.7688

[27] El Baz Mohamed, F., et al. (2015) Assessment of Hair Aluminum, Lead, and Mercury in a Sample of Autistic Egyptian Children: Environmental Risk Factors of Heavy Metals in Autism. Behavioural Neurology, 2015, Article ID: 545674.

[28] Lidsky, T.I. and Schneider, J.S. (2005) Autism and Autistic Symptoms Associated with Childhood Lead Poisoning. Journal of Applied Research in Clinical and Experimental Therapeutics, 5, 80-87.

[29] Lidsky, T.I. and Schneider, J.S. (2006) Adverse Effects of Childhood Lead Poisoning: The Clinical Neuropsychological Perspective. Environmental Reviews, 100, 284-293. https://doi.org/10.1016/j.envres.2005.03.002

[30] Blaurock-Busch, E., Amin, O.R., Dessoki, H.H. and Rabah, T. (2012) Toxic Metals and Essential Elements in Hair and Severity of Symptoms among Children with Autism. Maedica, 7, 38-48.

[31] Mason, L.H., Harp, J.P. and Han, D.Y. (2014) Pb Neurotoxicity: Neuropsychological Effects of Lead Toxicity. Biomed Research International, 2014, Article ID: 840547. https://doi.org/10.1155/2014/840547

[32] Lidsky, T.I. and Schneider, J.S. (2003) Lead Neurotoxicity in Children: Basic Mechanisms and Clinical Correlates. Brain, 126, 5-19.

[33] Blaurock-Busch, E., Amin, O.R., Dessoki, H.H. and Rabah, T. (2012) Toxic Metals and Essential Elements in Hair and Severity of Symptoms among Children with Autism. Maedica: A Journal of Clinical Medicine, 7, 38-48. 